\title{
Penerapan Model Pembelajaran Project Based Learning (PjBL) Terhadap Pemahaman Konsep Siswa Pada Materi Suhu dan Kalor
}

\author{
Sonia $^{1}$, Yudi Kurniawan ${ }^{2}$, Riski Muliyani ${ }^{3}$ \\ STKIP Singkawang \\ soniaqholid21@gmail.com ${ }^{1}$,yudikurniawan1012@gmail.com ${ }^{2}$, kikiriski1012@gmail.com
}

\section{Kata Kunci :}

Project Based Learning (PjBL), Pemahaman Konsep Siswa,

Suhu dan Kalor

\begin{abstract}
ABSTRAK
Penelitian ini bertujuan untuk mendapatkan gambaran mengenai peningkatan aspek pemahaman konsep siswa setelah diterapkan model pembelajaran Project Based Learning (PjBL) pada materi suhu dan kalor. Penelitian menggunakan metode weak-experiment design dengan desain penelitian one group pretest-posttest design. Populasi penelitian adalah seluruh siswa kelas VII disalah satu MTS Singkawang dengan teknik pengambilan sampel berupa teknik cluster sampling. Penelitian dilakukan di kelas VII H yang berjumlah 23 orang siswa. Instrumen yang digunakan berupa tes pemahaman konsep objektif 18 pilihan ganda. Penelitian ini menemukan bahwa pemahaman konsep siswa mengalami peningkatan disemua aspek. Peningkatan nilai tertinggi terdapat pada aspek pemahaman konsep menafsirkan yang nilai $N$-gain-nya sebesar 0,7 dengan kategori tinggi. Pada aspek mencontohkan sebesar 0,5 dengan kategori sedang, aspek mengklasifikasikan sebesar 0,4 dengan kategori sedang, aspek menyimpulkan sebesar 0,6 dengan kategori sedang, aspek membandingkan sebesar 0,3 dengan kategori sedang, dan nilai terendah terdapat pada aspek menjelaskan yang nilai $N$-gain-nya sebesar 0,2 dengan kategori rendah. Dengan demikian, model pembelajaran Project Based Learning (PjBL) dapat dijadikan sebagai alternatif dalam meningkatkan kemampuan pemahaman konsep siswa pada materi suhu dan kalor.
\end{abstract}

\section{PENDAHULUAN}

Pembelajaran IPA di SMP/MTS menuntut siswa mampu memahami konsep, menunjukkan sikap ilmiah mengajukan pertanyaan serta melakukan pengamatan tentang alam sekitar dan mampu menyajikan laporan data hasil pengamatan secara sederhana (Permendikbud, 2016). Pembelajaran seharusnya bisa dijadikan wahana dalam penguasaan konsep yang berguna untuk memecahkan masalah dalam kehidupan sehari-hari. Hal ini dikarenakan penguasaan konsep merupakan kemampuan yang esensial dalam sebuah pembelajaran harus dimiliki oleh siswa (Susana et al., 
2015). Didukung oleh Muliyani, (2018) bahwa pemahaman konsep sangat penting dalam proses belajar karena tingkat capaian hasil belajar siswa pada taksonomi versi Anderson menjadi dasar struktur kognitif yang kuat agar mampu menyimpan informasi yang telah diselidiki kapan saja dengan jangka waktu yang lebih lama.

Satu diantara cabang pembelajaran IPA, khususnya Fisika membahas tentang konsep-konsep fisika dan hukum-hukum fisika sebagai produk serta melakukan pengamatan, percobaan, dan penyelidikan sebagai proses (Hastuti et al., 2017). Mempelajari fisika tanpa memahami konsepkonsep tidaklah sesuai dengan hakekat IPA sebagai produk dan proses serta tidak sesuai dengan proses belajar bermakna (Ma'rifa et al., 2016). Dalam pembelajaran IPA, khususnya Fisika pemahaman konsep sangat penting untuk dilatihkan (Mariana, 2017). Menurut Suranti et al., (2017) alasan mengapa pemahaman konsep penting untuk dilatihkan karena siswa tidak hanya sebatas mengetahui konsepnya saja akan tetapi seseorang menguasai suatu konsep agar ia mampu berkomunikasi, mengklasifikasikan ide, gagasan atau peristiwa yang dialaminya dalam kehidupan sehari-hari. Didukung oleh Sastrika et al., (2013) bahwa pemahaman konsep itu penting untuk dilatihkan karena pemahaman konsep merupakan salah satu aspek yang perlu mendapatkan perhatian di dalam pembelajaran karena akan berujung pada hasil belajar siswa.

Rendahnya pemahaman konsep disebabkan karena penggunaan model pembelajaran yang kurang sesuai dengan kemampuan siswa membuat suasana belajar yang monoton bahkan kadang membosankan dan kurangnya minat belajar siswa (Suranti et al., 2017). Didukung oleh Restami et al., (2013) faktor yang dapat menyebabkan rendahnya pemahaman konsep siswa satu diantaranya adalah model pembelajaran yang diterapkan guru, sehingga dalam proses pembelajaran guru lebih aktif dibanding siswa (teacher centered) dengan metode pembelajaran yang cenderung menoton dan kurang melibatkan siswa menemukan suatu konsep dalam proses pembelajaran.

Pemahaman merupakan hasil dari proses pembelajaran yang mempunyai indikator dan setiap individu dapat mengartikan suatu bagian informasi dengan kata-kata sendiri (Alatas, 2014). Indikator pemahaman konsep terdiri dari tujuh aspek, yaitu menafsirkan, mencontohkan, mengklasifikasikan, merangkum, menyimpulkan, membandingkan, dan menjelaskan (Anderson, W.L., \& Krathwohl, 2010) . Anderson dan Krathwohl (2010) juga mengungkapkan bahwa siswa memahami konsep ketika mereka menghubungkan pengetahuan baru dan pengalaman lama serta mampu mengkonstruksi makna dari pembelajaran baik dalam bentuk tulisan, lisan maupun gambar, yang disampaikan melalui pembelajaran langsung maupun media.

Salah satu prinsip dalam melaksanakan pendidikan adalah siswa secara aktif mengambil bagian dalam kegiatan belajar mengajar itu sendiri (Iman, et al., 2017). Hal ini tentunya berdampak pada minat belajar siswa dalam menerima pelajaran fisika yang menyebabkan rendahnya penguasaan konsep siswa untuk menyelesaikan suatu persoalan (Suranti et al., 2017). Masalah rendahnya pemahaman konsep siswa perlu dicari solusinya agar pembelajaran yang dilakukan dapat mencapai hasil yang maksimal dan mampu meningkatkan pemahaman konsep siswa. Maka perlu suatu model pembelajaran yang mampu memberikan kesempatan kepada siswa berdasarkan pengalaman nyata yang dimiliki oleh siswa, sehingga pembelajaran akan menjadi lebih efektif. Model pembelajaran Project Based Learning (PjBL) merupakan pembelajaran inovatif yang berpusat pada siswa (student centered) dan menempatkan guru sebagai motivator dan fasilitator, di mana siswa diberi peluang bekerja secara otonom mengkonstruksi belajarnya (Suranti et al., 2017). Model pembelajaran berbasis proyek mampu memberikan nilai pemahaman konsep yang lebih baik dibandingkan dengan model pembelajaran konvensional (Sastrika et al., 2013).

Model pembelajaran Project Based Learning yang dikembangkan oleh (The George Lucas Educational Foundation, 2005) terdapat enam tahapan yaitu sebagai berikut, 1)Membuka pelajaran dengan suatu pertanyaan menantang (start eith the big question), 2)Merencanakan proyek (design a plan for the project), 3)Menyusun jadwal aktivitas (create a schedule), 4)Mengawasi jalannya proyek (monitor the students and the progress of the project), 5) Penilaian terhadap produk yang dihasilkan (assess the outcome), 6) Evaluasi (evaluate the experience). Pada tahapan monitoring merupakan tahapan model Project Based Learning yang dapat meningkatkan pemahaman konsep siswa. Sesuai dengan penelitian Sastrika et al., (2013) model pembelajaran Project Based Learning mengacu pada pembelajaran konstruktivisme dan bermakna dimana pendidik lebih banyak berposisi 
sebagai pengarah, pembimbing, pemberi fasilitas, dan motivator dalam pembelajaran sehingga sangat berpotensi untuk membangun konsep pada diri siswa secara mandiri untuk menghasilkan pengetahuan baru dan memperdalam pemahaman konsep.

Berdasarkan hal tersebut, maka penelitian ini bertujuan untuk mendapatkan gambaran mengenai peningkatan aspek pemahaman konsep siswa setelah diterapkan model Project Based Learning (PjBL) pada materi suhu dan kalor.

\section{METODE PENELITIAN}

Jenis penelitian ini adalah penelitian kuantitatif, metode yang digunakan pada penelitian ini adalah weak experiment design. Metode weak experiment design merupakan metode eksperimen yang tidak mempunyai variabel kontrol.

Desain penelitian yang digunakan pada penelitian ini adalah desain one group pretest-posstest design. Desain ini mencakup satu kelompok yang diobservasi pada tahap pretest kemudian dilanjutkan dengan treatmen dan posttest (Creswell, 2009). Sampel dalam penelitian diberi perlakuan (treatmen) yaitu penerapan model Project Based Learning (PjBL) terhadap pemahaman konsep siswa selama waktu tertentu. Pelaksanaan pretest dilakukan sebelum pemberian treatmen. Desain penelitian dapat dilihat pada Tabel 1. Sebagai berikut.

Tabel 1. Desain Penelitian One Group Pretest-Posttset Design

\begin{tabular}{ccc}
\hline Pre-Test & Treatment & Post-Test \\
\hline $\mathrm{O}$ & $\mathrm{X}$ & $\mathrm{O}$ \\
\hline
\end{tabular}

Keterangan:

O : Tes Pemahaman Konsep

$\mathrm{X} \quad$ : Treatment menggunakan model Project Based Learning (PjBL)

Populasi dalam penelitian adalah seluruh siswa kelas VII MTS Kota Singkawang. Sampel dalam penelitian ini dipilih satu kelas dari seluruh siswa kelas VII MTS Kota Singkawang. Adapun teknik pengambilan sampel dalam penelitian ini adalah cluster sampling. Teknik penarikan sampel dengan menggunakan metode ini, populasi dibagi terlebih dahulu atas kelompok berdasarkan area atau cluster, lalu beberapa cluster dipilih sebagai sampel, dari cluster tersebut diambil seluruh atau sebagian saja untuk dijadikan sampel, anggota populasi di setiap cluster tidak perlu homogen.

Instrumen yang digunakan adalah tes pemahaman konsep siswa yang terdiri dari 18 soal pilihan ganda dengan 4 pilihan (A, B, C dan $\mathrm{D})$. Tes ini mengukur aspek menafsirkan, mencontohkan, mengklasifikasikan, menyimpulkan, membandingkan, dan menjelaskan, dimana setiap aspek tersebut tersebar merata. terhadap model pembelajaran Project Based Learning (PjBL). Soal tes pemahaman konsep dan angket respon siswa dibuat oleh saya sendiri.

Untuk menentukan peningkatan aspek pemahaman konsep siswa setelah diterapkan model pembelajaran pembelajaran Project Based Learning (PjBL) dengan menggunakan rumus N-Gain yang dikembangkan oleh (Hake, 1998) pada persamaan berikut.

$$
<g>=\frac{S_{\text {post-test }}-S_{\text {pre-test }}}{S_{\text {maksimum }}-S_{\text {pre-test }}}
$$


Keterangan:

$\begin{array}{cl}\langle g\rangle & : \text { gain ternormalisasi } \\ S_{\text {post-test }} & \text { : skor tes akhir } \\ S_{\text {pre-test }} & : \text { skor tes awa } \\ S_{\text {maksimum }} & : \text { skor maksimum dari skor tes awal dan skor tes akhir }\end{array}$

Kategori peningkatan gain yang dinormalisasi (n-gain) untuk menyatakan peningkatan kemampuan pemahaman konsep siswa pada materi Suhu dan kalor dapat disajikan pada Tabel. 2.

Tabel 2. Kategori Peningkatan Pemahaman Konsep siswa

\begin{tabular}{cc}
\hline Gain & Kategori \\
\hline$(\mathrm{g}) \geq 0,7$ & Tinggi \\
$0,3 \leq(\mathrm{g})<0,7$ & Sedang \\
$(\mathrm{g})<0,3$ & Rendah \\
\hline
\end{tabular}

\section{HASIL DAN PEMBAHASAN}

Data hasil aspek pemahaman konsep siswa diperoleh dari rata-rata skor hasil pretest dan rata-rata posttest yang dinormalisasi sebelum dan sesudah penerapan model pembelajaran PjBL. Berdasarkan perhitungan diperoleh bahwa skor rata-rata tes aspek pemahman konsep siswa setelah dinormalisasi dengan menggunakan persamaan (1) diperoleh nilai sebesar 0,5 dengan kategori sedang.

Berdasarkan hasil analisis data yang diperoleh dari penelitian diungkapkan bahwa pemahaman konsep siswa setelah dinormalisasi dengan uji N-gain diperoleh peningkatan pada setiap aspeknya. Pada aspek menafsirkan sebesar 0,7 dengan kategori tinggi, pada aspek mencontohkan sebesar 0,5 dengan kategori sedang, aspek mengklasifikasikan sebesar 0,4 dengan kategori sedang, aspek menyimpulkan sebesar 0,6 dengan kategori sedang, aspek membandingkan sebesar 0,3 dengan kategori sedang, dan nilai terendah terdapat pada aspek menjelaskan yang nilai $\mathrm{N}$-gain-nya sebesar 0,2 dengan kategori rendah. Hal ini membuktikan bahwa model pembelajaran PjBL dapat meningkatkan pemahaman konsep siswa kelas VII pada materi Suhu dan Kalor. Adapun data skor $\mathrm{N}$ gain terhadap hasil aspek pemahaman konsep siswa pada pada grafik berikut.

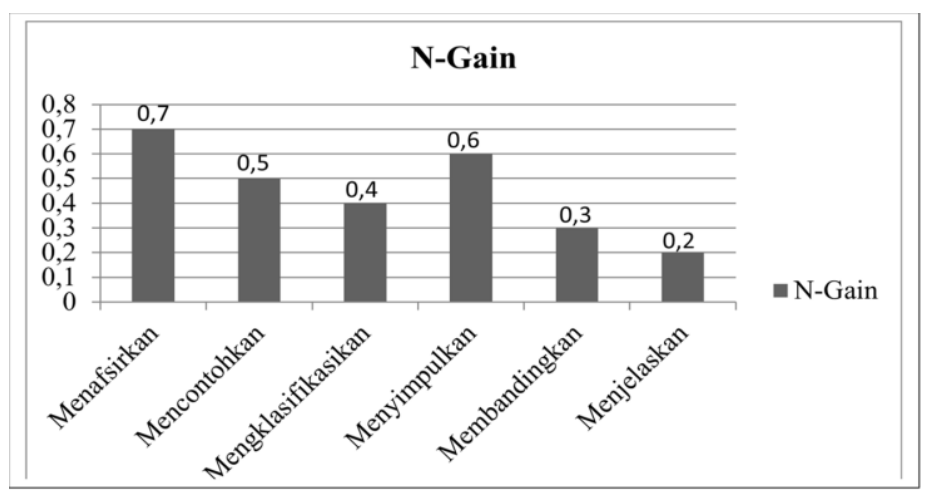

Gambar 1. Skor N-gain aspek pemahaman konsep siswa

Berdasarkan Gambar 1 tampak bahwa aspek pemahaman konsep siswa mengalami peningkatan paling rendah terdapat pada aspek menjelaskan dengan kategori rendah. Rendahnya Rendahnya peningkatan pada aspek menjelaskan karena siswa kurang percaya diri dalam mengemukakan pendapat atau gagasan konseptual yang dimilikinya dan juga hasil posttest yang tidak menunjukkan hasil yang tinggi. Pratiwi et al., (2012) menyatakan bahwa pada setiap aspek yang tidak mengalami peningkatan atau terjadi peningkatan yang sedikit disebabkan oleh tingkat kemudahan dan tingkat pemahaman konsep siswa yang berbeda antara satu dan lainnya. 
Pengetahuan yang dimiliki oleh siswa juga berperan terhadap tingginya aspek menafsirkan pada penelitian ini. Pada aspek menafsirkan juga dilatihkan pada tahapan monitoring. Pada tahapan monitoring merupakan tahapan model pembelajaran Project Based Learning (PjBL), pada tahapan ini guru memfasilitasi aktivitas siswa dalam menyelesaikan proyek, dalam tahapan ini siswa melakukan tahapan-tahapan proyek yang disediakan oleh guru melalui LKS berbasis Project Based Learning (PjBL) serta menyelesaikan beberapa permasalahan di LKS yang diisi oleh siswa pada setiap kelompok. Hal ini sejalan dengan pendapat Sani (2013) salah satu keuntungan yang diperoleh dengan menerapkan model pembelajaran Project Based Learning adalah dapat meningkatkan kemampuan siswa dalam menyelesaikan masalah dan memberikan kesempatan belajar bagi siswa untuk berkembang sesuai kondisi dunia nyata.

Perbedaan pemahaman konsep siswa disebabkan kemampuan karakteristik seseorang yang berbeda, cara berperilaku atau berpikir dalam situasi dan berlangsung terus dalam periode waktu yang lama yang mengakibatkan kemampuan konsep siswa yang satu berbeda dengan lainnya (Uno, 2019). Didukung oleh Sucipta et al., (2014) bahwa pemahaman konsep setiap siswa berbeda dikarenakan kemampuan individu siswa yaitu kemampuan intelektual siswa, kemampuan fisik, latar belakang keluarga, kebiasaan dan pendekatan belajar setiap siswa yang mengakibatkan kemampuan konsep siswa yang satu berbeda dengan lainnya.

\section{SIMPULAN DAN SARAN}

Penerapan model pembelajaran Project Based Learning (PjBL) dapat meningkatkan pemahaman konsep siswa pada materi Suhu dan Kalor dengan nilai rata-rata $\mathrm{N}$-gain sebesar 0,5 kategori sedang. Hal ini ditunjukkan dengan hasil analisis $\mathrm{N}$-gain yaitu pada aspek menafsirkan sebesar 0,7 dengan kategori tinggi, aspek mencontohkan sebesar 0,5 dengan kategori sedang, aspek mengklasifikasikan sebesar 0,4 dengan kategori sedang, aspek menyimpulkan sebesar 0,6 dengan kategori sedang, aspek membandingkan sebesar 0,3 dengan kategori sedang, dan aspek menjelaskan sebesar 0,2 dengan kategori rendah.

Sebaiknya Project Based Learning (PjBL) dapat dipilih sebagai alternatif model pembelajaran yang dapat dilaksanakan di sekolah, sebab dengan model pembelajaran Project Based Learning (PjBL) dapat meningkatkan pemahaman konsep siswa. Selain itu, model pembelajaran Project Based Learning (PjBL) dapat digunakan pada materi IPA yang lain untuk mengetahui penerapan pemahaman konsep dalam proses pembelajaran.

\section{DAFTAR PUSTAKA}

Aini, Q., Lesmono, A. D., \& Wahyuni, S. (2018). Hasil Belajar, Minat Dan Kreativitas Siswa Sma Pada Pembelajaran Fisika Menggunakan Model Project Based Learning Dengan Memanfaatkan Bahan Bekas. Jurnal Pembelajaran Fisika, $7(1), \quad 1$. https://doi.org/10.19184/jpf.v7i1.7218

Alatas, F. (2014). Hubungan Pemahaman Konsep dengan Keterampilan Berpikir Kritis Melalui Model Pembelajaran Treffinger pada Mata Kuliah Fisika Dasar. Edusains, 6(1), 88-96.

Anderson, W.L., \& Krathwohl, D. R. (2010). Pembelajaran, pengajaran, dan asesmen. Pustaka Pelajar. YOGYAKARTA: PUSTAKA

Fraenkel, J. R., \& Wallen, N. E. (2008). How To Design And Evaluate Research In Education (Seventh). ELVIRA, cv.

Hake, R. R. (1998). Interactive-engagement versus traditional methods: A six-thousand-student survey of mechanics test data for introductory physics courses. American Journal of Physics, 66(1), 64-74. https://doi.org/10.1119/1.18809

Hastuti, A., Sahidu, H., \& Gunawan, G. (2017). Pengaruh Model PBL Berbantuan Media Virtual Tehadap Kemampuan Pemecahan Masalah Fisika. Jurnal Pendidikan Fisika Dan Teknologi, 2(3), 129. https://doi.org/10.29303/jpft.v2i3.303 
Iman, R., Khaldun, I., \& Nasrullah, N. (2017). Meningkatkan Kemampuan Berpikir Kritis Siswa dengan Model Inkuiri Terbimbing pada Materi Pesawat Sederhana. Jurnal Pendidikan Sains Indonesia (Indonesian Journal of Science Education), 5(1), 52-58.

Ma'rifa, Kamaluddin, H. \& Fihrin, H. (2013). Analisis Pemahaman Konsep Gerak Lurus pada Siswa SMA Negeri di Kota Palu. Jurnal Pendidikan Fisika Tadulako, 4(3) :1-3

Mariana, N. (2017). PENERAPAN MODEL PEMBELAJARAN LEVELS OF INQUIRY (LoI) PADA MATERI FLUIDA STATIS UNTUK MENINGKATKAN PEMAHAMAN KONSEP DAN PENALARAN ILMIAH SISWA SMP SATU ATAP. PendidikanIndonesiarepository.upi.

Muliyani, R. (2018). Signifikansi Discovery Learning Vs Guided Discovery Learning Terhadap Peningkatan Pemahaman Konsep. Gravity: Jurnal Ilmiah Penelitian dan Pembelajaran Fisika, 4(1).

Permendikbud. (2016). PERATURAN MENTERI PENDIDIKAN DAN KEBUDAYAAN NOMOR 21 TAHUN 2016. 62(1), 27-40.

Pratiwi, L., \& Handayani, L. (2012). Efektivitas model pembelajaran eksperimen inkuiri terbimbing berbantuan my own dictionary untuk meningkatkan penguasaan konsep dan unjuk kerja siswa SMP RSBI. Unnes Science Education Journal, 1(2).

Restami, P. M,. Suma, K. \& Pujani, M. (2013). Pengaruh Model Pembelajaran POE (Predict-ObserveExplaint) Terhadap Pemahaman Konsep Fisika dan Sikap ailmiah Ditinjau dari GAya Belajar Siswa. e- Journal Program Pascasarjana Universitas Pendidikan Ganesha, 3(1) :1-11

Sani, Ridwan Abdullah. 2014. Pembelajaran Saintifik Untuk Implementasi Kurikulum 2013. Jakarta: Bumi Aksara

Sastrika, I. A. K., Sadia, I. W., \& Muderawan, I. W. (2013). Pengaruh model pembelajaran berbasis proyek terhadap pemahaman konsep kimia dan keterampilan berpikir kritis. E-Journal Program Pascasarjana Universitas Pendidikan Ganesha, 3(2), 194-204.

SUCIPTA, A. A. G. N., Suastra, I. W., \& Sadia, I. W. (2014). Pengaruh Model Pembelajaran Heuristik Vee Terhadap Pemahaman Konsep Fisika dan Sikap Ilmiah Siswa SMA. Jurnal Pendidikan dan Pembelajaran IPA Indonesia, 4(1).

Suranti, N. M. Y., Gunawan, G., \& Sahidu, H. (2017). Pengaruh Model Project Based Learning Berbantuan Media Virtual Terhadap Penguasaan Konsep Peserta didik pada Materi Alat-alat $\begin{array}{llllll}\text { Optik. Jurnal Pendidikan Fisika Dan Teknologi, } & 73 .\end{array}$ https://doi.org/10.29303/jpft.v2i2.292

Susana, E. S. H. \& Sriyansyah. (2015). Analisis Didaktis Berdasarkan Kemampuan Kognitif dan Keterampilan Berpikir Kritis Siswa pada Materi Kalor. Jurnal Penelitian \& Pengembangan Pendidikan Fisika (JPPPF). l(2), 39-44

The George Lucas Educational Foundation 2007. How Does Project Based Learning Work. http://www.edupotia.org/project-based-learning-guide-implementation. (diakses 3 juli 2020)

Uno, Hamzah B. (2019). Model Pembelajaran Menciptakan Proses Belajar Mengajar yang Kreatif dan Efektif. Jakarta: Bumi Aksara. 